\title{
Embolic renal infarction mimicking renal colic
}

This article was published in the following Dove Press journal: International Journal of Nephrology and Renovascular Disease 30 April 2014

Number of times this article has been viewed

\author{
Mahmud Mahamid ${ }^{1,3}$ \\ Adi Francis ${ }^{2}$ \\ Ali Abid' \\ Mohammed Awawde' \\ Omar Abu-Elhija' \\ 'Department of Internal Medicine, \\ ${ }^{2}$ Cardiac Care Unit, Holy Family \\ Hospital, Bar-Ilan University, Nazareth, \\ Israel; ${ }^{3}$ Digestive Disease Institute, \\ Liver Unit, Shaare Zedek Medical \\ Center, Jerusalem, Israel
}

Correspondence: Mahmud Mahamid Digestive Disease Institute, Liver Unit, Shaare Zedek Medical Center, POB 3235, Jerusalem, Israel Emailmahmudmahamid@yahoo.com

\begin{abstract}
Atrial fibrillation is a major health problem with risk of systemic arterial embolism. Acute embolic renal infarction is a rare condition with symptoms that are often nonspecific. We present a 36-year-old previously healthy man with acute embolic renal infarction secondary to new onset atrial fibrillation, who presented with flank pain mimicking renal colic. The patient was treated successfully with anticoagulation therapy, beta-blockers, broad-spectrum antibiotics, and supportive treatment.
\end{abstract}

Keyword: atrial fibrillation

\section{Introduction}

Atrial fibrillation (AF) carries a substantial risk of systemic arterial embolism. Acute embolic renal infarction has been reported as a complication of uncontrolled AF. ${ }^{1}$ However, its incidence is rare, and its nonspecific symptoms suggest that it may often be misdiagnosed. ${ }^{2,3}$

We present a patient with acute embolic renal infarction secondary to AF complicating a nondiagnosed rheumatic mitral stenosis, who presented with flank pain mimicking renal colic.

\section{Case report}

A 36-year-old previously healthy man presented to the emergency department of our hospital with complaints of right flank pain and right lower quadrant abdominal pain. There were no complaints of fever, dysuria, nausea, or vomiting. There was no history of nephrolithiasis. His vital signs showed a blood pressure of 122/76 $\mathrm{mmHg}$ and a regular pulse of $120 \mathrm{bpm}$. Urinalysis showed mild hematuria with no signs of infection. Blood tests including complete blood count, electrolytes, and renal function were all normal. A plain abdominal X-ray was normal. The patient was clinically diagnosed as suffering from right renal colic and was treated with diclofenac for symptomatic relief and was discharged home for further ambulatory urologic investigation.

A few hours later the patient returned to the emergency department with severe right flank pain, dyspnea, and palpitations. On physical examination his radial pulse was irregular at $120 \mathrm{bpm}$, his blood pressure was 133/82 $\mathrm{mmHg}$, and his body temperature was $36.8^{\circ} \mathrm{C}$. Chest auscultation revealed irregular heart sounds: a $3 / 6$ systolic murmur at the cardiac apex and a diastolic apical murmur of $2 / 6$. His lungs were clear to auscultation. Palpation of the right flank produced moderately intense pain. The electrocardiogram showed AF with ventricular response of $115 \mathrm{bpm}$ and a QRS pattern 
of right ventricular hypertrophy. Urinalysis showed hematuria and mild leukocyturia. Blood tests including urea, creatinine, electrolytes, and liver function were normal. Lactate dehydrogenase was significantly elevated at 2,780 U/L (normal 211-480 U/L). Complete blood count revealed mild leukocytosis, $11.9 \times 10^{9} / \mathrm{L}$ (normal $4.4-11.3 \mathrm{~L}$ ), with $88.9 \%$ neutrophils (normal 50\%-70\%). The patient was treated with analgesics without relief. Subsequent urine and blood cultures were clear. Transthoracic echocardiography showed preserved left ventricular function, dilated left atrium with no demonstrated thrombi, moderate to severe mitral stenosis, and moderate mitral regurgitation, with degenerative mitral valve changes compatible with rheumatic heart disease. Due to persistent flank pain, a computerized tomography scan with intravenous contrast injection was performed and showed multiple hypodense areas in the right kidney, with triangular configurations compatible with right renal infarctions (Figure 1). The patient was treated with low molecular weight heparin, warfarin, beta-blockers, broad spectrum antibiotics, and hydration. His condition gradually improved to full recovery. A week later, the patient was discharged home on warfarin and in good health.

\section{Discussion}

The earliest report of renal embolic disease was published by Traube in $1856,{ }^{5}$ and since then, many case reports have been published. Hoxie and Coggin reported 205 cases of renal infarction identified in 14,411 autopsies, presenting an incidence of $1.4 \%$; however, the lesion was diagnosed clinically in only two patients. 5,7

The diagnosis of acute renal infarction may often be missed. The nonspecific presentation and a low incidence often lead to an incorrect diagnosis of nephroureterolithiasis, pyelonephritis, diverticulitis, or appendicitis. Renal artery thrombosis or thromboembolism are the main causes of renal

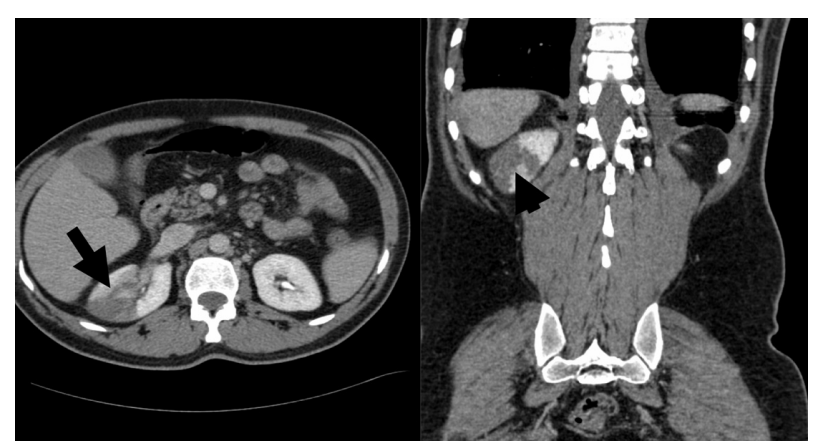

Figure I Peripheral diminished density without enhancement in right kidney. Note: Arrows show peripheral renal infarction. infarction, therefore, any associated medical illness with increased risk for systemic thromboembolism should prompt an increased suspicion of the diagnosis, as with our case. ${ }^{1,4}$

Renal infarction secondary to thromboembolism is usually a sequel of cardiac disease; the three major causes are atrial fibrillation, acute myocardial infarction, and rheumatic mitral stenosis. ${ }^{1,4}$ Other causes include paradoxical cardiac emboli complicating atrial septal defects, peripheral arterial emboli dislodging from aortic mobile atheromas, or thrombi dislodging from left ventricular wall aneurysms related to acute myocardial infarction or acute apical ballooning (takotsubo syndrome). Renovascular disease and malignant hypertension have been also described as possible causes of renal infarction.

Lactate dehydrogenase appears to be the most sensitive but not specific laboratory test for renal infarction. Elevation to more than 2,000 U/L can occur early, within an hour and can persist for 14 days. Other laboratory test abnormalities associated with renal infarction include leukocytosis, elevated creatine phosphokinase, and hematuria, but since these are all common and nonspecific, they are not helpful.,

Contrast enhanced computer tomography is the noninvasive standard imaging method used for making the diagnosis of renal infarction. The classic finding is peripheral diminished density without enhancement. ${ }^{6,7}$ The main differential diagnosis for such findings is hypoenhancement due to infection (lobar nephronia/pyelonephritis). However, these patients often present with predominant inflammatory symptoms.

The delay in the proper diagnosis of renal infarction decreases the chances of proper treatment and renal salvage. $^{5}$

The therapeutic guidelines for renal artery embolism are not established. Treatment options include systemic anticoagulation, thrombolytic therapy, and surgical embolectomy for renal artery occlusion. ${ }^{6-9}$

\section{Conclusion}

Acute renal infarction secondary to AF is a rare clinical condition. Its clinical presentation can be confused with other diseases with similar initial symptoms, and this may delay the diagnosis and treatment. A high index of clinical suspicion is important to make the diagnosis and successfully treat the patient.

\section{Disclosure}

The authors report no conflicts of interest in this work. 


\section{References}

1. Meyrier A, Hill GS, Simon P. Ischemic renal diseases: new insights into old entities. Kidney Int. 1998;54(1):2-13.

2. Kusaba T, Kimura K. [Renal infarction: Pathogenesis, pathophysiology, and therapy]. Nihon Rinsho. 2006;64(Suppl 2):473-476. Japanese.

3. Scolari F, Ravani P. Atheroembolic renal disease. Lancet. 2010; 375(9726):1650-1660.

4. Turina S, Mazzola G, Venturelli C, et al. [Atheroembolic renal disease]. G Ital Nefrol. 2009;26(2):181-190. Italian.

5. Antopolsky M, Simanovsky N, Stalnikowicz R, Salameh S, Hiller N. Renal infarction in the ED: 10-year experience and review of the literature. Am J Emerg Med. 2012;30(7):1055-1060.
6. Dörrler J, Wahba A. [Diagnosis and treatment of visceral and renal embolisms]. Herz. 1991;16(6):425-433. German.

7. Jeffrey RB, Federle MP. CT and ultrasonography of acute renal abnormalities. Radiol Clin North Am. 1983;21(3):515-525.

8. Holden A. Is there an indication for embolic protection in renal artery intervention? Tech Vasc Interv Radiol. 2011;14(2):95-100.

9. Gutiérrez Solís E, Morales E, Rodríguez Jornet A, et al. [Atheroembolic renal disease: analysis of clinical and therapeutic factors that influence its progression]. Nefrologia. 2010;30(3):317-323. Spanish.

\section{Publish your work in this journal}

The International Journal of Nephrology and Renovascular Disease is an international, peer-reviewed open-access journal focusing on the pathophysiology of the kidney and vascular supply. Epidemiology, screening, diagnosis, and treatment interventions are covered as well as basic science, biochemical and immunological studies. The journal welcomes original research, clinical studies, reviews \& evaluations, expert opinion and commentary, case reports and extended reports. The manuscript management system is completely online and includes a very quick and fair peerreview system, which is all easy to use. Visit http://www.dovepress.com/ testimonials.php to read real quotes from published authors.

Submit your manuscript here: http://www.dovepress.com/international-journal-of-nephrology-and-renovascular-disease-journal 